\title{
Decreased serum level of nitric oxide in children with excessive body weight
}

\author{
Aleksandra Czumaj ${ }^{1, A-D, F}$, Marta Śledzińska ${ }^{2, B, E, F}$, Michał Brzezińskij ${ }^{3, B, E, F}$, \\ Agnieszka Szlagatys-Sidorkiewicz 2,B,E,F, Ewa Słomińska ${ }^{4, C, E, F}$, Tomasz Śledziński ${ }^{1, A, D-F}$ \\ ${ }^{1}$ Department of Pharmaceutical Biochemistry, Faculty of Pharmacy, Medical University of Gdańsk, Poland \\ 2 Department of Pediatrics, Pediatric Gastroenterology, Hepatology and Nutrition, Faculty of Medicine, Medical University of Gdańsk, Poland \\ ${ }^{3}$ Department of Public Health and Social Medicine, Faculty of Health Sciences, Medical University of Gdańsk, Poland \\ ${ }^{4}$ Department of Biochemistry, Faculty of Medicine, Medical University of Gdańsk, Poland \\ A - research concept and design; B - collection and/or assembly of data; C - data analysis and interpretation; \\ $D$ - writing the article; $E$ - critical revision of the article; $F$ - final approval of the article
}

\section{Address for correspondence}

Tomasz Śledziński

E-mail: tsledz@gumed.edu.pl

\section{Funding sources}

This work was supported by Medical University

of Gdańsk under academic funds

(ST-60 and ST-40).

\section{Conflict of interest}

None declared

Received on January 13, 2017

Reviewed on July 12, 2017

Accepted on September 25, 2017

Published online on August 21, 2018

Cite as

Czumaj A, Śledzińska M, Brzeziński M, Szlagatys-Sidorkiewicz A, Słomińska E, Śledziński T. Decreased serum level of nitric oxide in children with excessive body weight. Adv Clin Exp Med. 2019;28(4):439-446. doi:10.17219/acem/77982

DOI

10.17219/acem/77982

\section{Copyright}

Copyright by Author(s)

This is an article distributed under the terms of the

Creative Commons Attribution Non-Commercial License

(http://creativecommons.org/licenses/by-nc-nd/4.0/)

\section{Abstract}

Background. Nitric oxide (NO) is an important mediator involved in vascular homeostasis. Changes in NO level are considered to be associated with obesity and its clinical consequences. Previous studies on N0 levels in obese children provided inconclusive results, so this issue requires clarification.

Objectives. One of the main goals of this study was to assess whether childhood excessive body weight (EBW) is associated with changes in serum NO level and whether features like age and gender are linked to NO levels in selected groups.

Material and methods. In the present study, the serum NO levels were compared in 43 children with EBW and 37 age- and gender-matched children with normal weight. Moreover, in both groups, body measurements and various clinical parameters, including the serum concentrations of arginine (Arg), a precursor of NO, were determined.

Results. The mean serum NO level in EBW group $(8.7 \pm 3.1 \mu \mathrm{mol} / \mathrm{L})$ was significantly lower than in normal weight group (22.2 $\pm 11.5 \mu \mathrm{mol} / \mathrm{L})$. However, the serum Arg concentrations were higher in EBW children than in controls. Serum asymmetric dimethylarginine (ADMA) levels were higher in EBW group and inversely correlated with serum NO. The EBW female subgroup was characterized by slightly lower level of NO than the EBW male subgroup. There were no significant changes in serum NO level among different age subgroups in both groups.

Conclusions. Our results revealed that EBW in children is associated with significantly decreased level of serum NO. The decreased serum NO level in EBW children is not a result of depleted Arg in the blood. Asymmetric dimethylarginine may at least partially contribute to decreased NO levels in children with EBW. A decreased level of NO could be a potential early marker of the risk of cardiovascular disorders developing in children with EBW.

Key words: children, overweight, cardiovascular risk, asymmetric dimethylarginine, nitric oxide 


\section{Introduction}

Obesity is a clinical condition defined as an abnormal and excessive accumulation of body fat and it is connected with a wide range of health consequences. ${ }^{1}$ For example, obesity (especially central body fatness) is a cardiovascular disease (CVD), diabetes and hypertension risk factor. ${ }^{2,3}$ Nowadays, obesity among children and juveniles is recognized as a worldwide epidemic. ${ }^{4,5}$ Excessive body weight (EBW) in young age can promote the premature development of CVD. Given the increasing concern for this fact in pediatrics, data on factors related to childhood obesity and early markers of pathological consequences of this complicated disorder is especially needed.

The nitric oxide (NO) is a free radical and a gaseous molecule with a short half-life time. In humans, NO is involved in a variety of physiological and pathological mechanisms. Nitric oxide is critically important in vascular homeostasis and vasomotor tone regulation. This molecule regulates endothelium-dependent vasodilation by the relaxation of smooth muscle cells. Due to this mechanism, NO level plays a role in the regulation of blood flow and blood pressure. Moreover, studies confirmed that NO can modulate cell interaction by decreasing platelet adhesion and aggregation. It is also associated with the suppression of smooth muscle cell proliferation. ${ }^{1,6}$ Nitric oxide is produced by NO synthase (NOS) during the transformation of $\mathrm{L}$-arginine into citrulline. Isoforms of this enzyme include: endothelial synthase (eNOS), neuronal synthase (nNOS) and inducible synthase (iNOS). ${ }^{1}$ Two of them (eNOS and nNOS) are constitutively expressed and calcium-dependent, and produce stable, low level of NO. In contrast, the $3^{\text {rd }}$ one (iNOS) is calcium-independent and is able to produce huge amounts of NO after induction. The eNOS is expressed primarily in endothelial cells whereas nNOS is expressed primarily in neurons. ${ }^{7}$ However, it has been confirmed that all 3 isoforms of NOS are also present in cardiomyocytes. ${ }^{8}$ NOS are competitively inhibited by natural methylated metabolite of arginine (Arg) - asymmetric dimethylarginine (ADMA). ${ }^{9}$ Changes in NO level have been considered to be associated with juvenile obesity and its clinical consequences like CVD, diabetes and hypertension. ${ }^{10}$ However, previous studies on NO levels in obese children provided inconclusive and contradictory results. Codoner-Franch et al. reported increased NO production in obese children, Gruber et al. described the reduction in bioavailability of $\mathrm{NO}$ in obese juveniles, whereas Belo et al. found no differences in NO level between obese and eutrophic children. ${ }^{11-13}$ Thus, this issue requires clarification.

In the present study, serum NO levels were compared in children with normal body weight and EBW in order to assess whether EBW in children influences NO level. It was also investigated whether features like age and gender are associated with NO levels in selected groups. In addition, we ascertained several other anthropometric and biochemical characteristics of patients in EBW and the normal weight group. Since Arg is a precursor of NO, its concentration in serum was also measured to check if it influences serum NO levels.

\section{Material and methods}

\section{Subjects}

Forty-three EBW and 37 normal weight age- and gender-matched children were included in this study. The mean age of the subjects was similar in EBW and normal weight group $(11.64 \pm 3.46$ and $11.20 \pm 3.98$ years, respectively). The patients were divided into subgroups according to their age (for EBW group: aged 5-9 $\mathrm{n}=15$, aged 10-14 $\mathrm{n}=13$ and aged 15-18 $\mathrm{n}=15$; for normal weight group: aged 5-9 n = 15, aged 10-14 n = 10 and aged $15-18 \mathrm{n}=12$ ) and gender (EBW group: female/ male $(F / M)=19 / 24$; normal weight group: $F / M=17 / 20)$. The participants of the study were recruited from the patients admitted to the Emergency Department, Orthopedic Ward and Department of Pediatrics, Pediatric Gastroenterology, Hepatology and Nutrition (Medical University of Gdańsk, Poland), with no clinical evidence of chronic diseases and acute infections in 2 weeks preceding blood collection. Children were admitted to the Emergency Department with the suspicion of foreign bodies present in the gastrointestinal tract. Patients from Orthopedic Ward were qualified to corrective surgery of bone alterations. The subjects were also recruited from children participating in a health program funded by Gdańsk City Council (6-10-14 Dla Zdrowia program). None of the children were receiving anti-inflammatory or hypotensive drugs. Basic information about the patients, such as age, gender, body weight, body height, and blood pressure, were recorded. Weight was measured to the nearest $100 \mathrm{~g}$ (patients were without shoes and minimally clothed). Body mass index (BMI) was calculated as weight in kilograms divided by height in square meters. Systolic blood pressure (SBP) and diastolic blood pressure (DBP) were measured after 10-15 min resting. The subjects were qualified to EBW or normal weight group based on the BMI percentile and in accordance with International Obesity Task Force (IOTF) criteria. ${ }^{14}$ The EBW was defined as a BMI greater than the $85^{\text {th }}$ percentile. All protocols of this study were carried out according to tenets of the Declaration of Helsinki of the World Medical Association.

\section{Blood collection}

Blood was collected after informed written consent was given by the patient's parent or legal guardian. Blood samples were obtained from all patients in the morning, after an overnight fast. Blood samples were obtained by venous puncture and centrifuged within $30-45 \mathrm{~min}$. Serum samples were stored at $-80^{\circ} \mathrm{C}$ until analysis. 


\section{Analytical procedures}

For the purpose of this study, we have assessed NO level in serum samples by an indirect method. Nitric oxide concentration was determined through its stable end products, nitrate and nitrite, by colorimetric detection of the Griess reaction product. ${ }^{15}$ Commercial assay Parameter ${ }^{\mathrm{TM}}$ Total Nitric Oxide and Nitrate/Nitrite from R\&D Systems was used (R\&D Systems Inc., Minneapolis, USA). The analysis was performed according to the manufacturer's instruction. Each sample was measured in duplicate.

Serum concentrations of Arg and other amino acids as well as ornithine and ADMA were determined using ion-pair high-performance liquid chromatography and mass spectrometry with electrospray ion source ThermoFinnigan LCQ Advantage (Thermo Scientific, Waltham, USA), as described previously. ${ }^{16}$

Selected biochemical parameters, i.e., glucose, insulin, total cholesterol, triglycerides (TG), creatinine, C-reactive protein (CPR), aspartate aminotransferase (ASAT) and alanine aminotransferase (ALAT), were measured by the Central Clinic Laboratory of the Medical University of Gdańsk, Poland. The homeostasis model assessment (HOMA) index was calculated as follows: (fasting glucose $[\mathrm{mmol} / \mathrm{L}] \times$ fasting insulin $[\mathrm{UE} / \mathrm{mL}]) / 22.5{ }^{17}$

\section{Statistical analysis}

Results are presented as a mean \pm standard deviation (SD) or are shown as box plots and the median. The adjustment to normality was verified by using the Kolmogorov-Smirnov test with Lilliefors correction. The significance of the differences between variables was tested by unpaired two-tailed t-test in case of normally distributed variables. The Mann-Whitney U test was used to compare non-normally distributed variables. For the comparison of multiple variables, analysis of variance (ANOVA) test was performed. The p-values less than 0.05 were considered statistically significant. It should be added that the power of unpaired two-tailed t-test was above 0.8. Correlations between selected parameters were determined by linear regression analysis (Pearson's method). All statistical analyses were performed with STATISTICA v. 10 (StatSoft Inc., Tulsa, USA).

\section{Results}

General anthropometric and biochemical data of normal weight and EBW children are presented in Table 1. As expected, significant differences were found between groups in terms of anthropometric measurements. Body mass index, centile BMI and weight were higher in EBW group than in normal weight group. Furthermore, the EBW children showed a significant increase in SBP and DBP in comparison to normal weight juveniles. The significant
Table 1. Anthropometric and biochemical characteristics of studied subjects

\begin{tabular}{|c|c|c|c|}
\hline Characteristic & $\begin{array}{l}\text { Normal } \\
\text { weight }\end{array}$ & $\begin{array}{c}\text { Excessive body } \\
\text { weight }\end{array}$ & $\mathrm{p}$-value \\
\hline Age [years] & $11.2 \pm 3.98$ & $11.6 \pm 3.46$ & 0.817 \\
\hline Gender (F/M) & $17 / 20$ & $19 / 24$ & - \\
\hline $\mathrm{BMI}\left[\mathrm{kg} / \mathrm{m}^{2}\right]$ & $17.6 \pm 2.83$ & $25.1 \pm 3.16$ & $0.000^{*}$ \\
\hline Centile BMI & $42.1 \pm 24.7$ & $95.8 \pm 3.05$ & $0.000^{*}$ \\
\hline Weight [kg] & $41.0 \pm 18.2$ & $59.5 \pm 19.3$ & $0.000^{*}$ \\
\hline $\mathrm{CRP}[\mathrm{mg} / \mathrm{L}]$ & $0.38 \pm 0.49$ & $1.37 \pm 1.03$ & $0.000^{*}$ \\
\hline Glucose [mg/dL] & $88.8 \pm 17.3$ & $91.0 \pm 7.48$ & 0.458 \\
\hline Insulin $[\mu \mid \mathrm{U} / \mathrm{mL}]$ & $9.86 \pm 7.32$ & $11.3 \pm 8.14$ & 0.432 \\
\hline HOMA index & $2.24 \pm 1.73$ & $2.60 \pm 2.01$ & 0.424 \\
\hline Cholesterol [mg/dL] & $154 \pm 29.6$ & $163 \pm 24.4$ & 0.169 \\
\hline $\mathrm{TG}[\mathrm{mg} / \mathrm{dL}]$ & $75.9 \pm 28.2$ & $88.4 \pm 44.1$ & 0.152 \\
\hline Creatinine $[\mathrm{mg} / \mathrm{dL}]$ & $0.58 \pm 0.16$ & $0.65 \pm 0.09$ & $0.005^{*}$ \\
\hline ASAT [U/L] & $21.7 \pm 7.79$ & $21.1 \pm 6.79$ & 0.706 \\
\hline ALAT [U/L] & $8.85 \pm 2.89$ & $15.9 \pm 6.08$ & $0.000^{*}$ \\
\hline $\mathrm{SBP}[\mathrm{mm} \mathrm{Hg}]$ & $98.9 \pm 16.2$ & $117 \pm 15.4$ & $0.000^{*}$ \\
\hline $\mathrm{DBP}[\mathrm{mm} \mathrm{Hg}]$ & $66.0 \pm 11.2$ & $73.3 \pm 11.5$ & $0.008^{*}$ \\
\hline Lys [ $\mu \mathrm{mol} / \mathrm{L}]$ & $87.5 \pm 26.7$ & $106 \pm 24.7$ & $0.007^{*}$ \\
\hline Total aa [ $\mathrm{mol} / \mathrm{L}]$ & $2,148 \pm 454$ & $2,360 \pm 375$ & 0.282 \\
\hline Ornithine $[\mu \mathrm{mol} / \mathrm{L}]$ & $71.5 \pm 23.5$ & $61.2 \pm 19.8$ & 0.065 \\
\hline Arg/ADMA ratio & $67.6 \pm 25.1$ & $73.9 \pm 30.6$ & 0.406 \\
\hline
\end{tabular}

$\mathrm{BMI}$ - body mass index; CRP - C-reactive protein; HOMA - homeostasis model assessment; TG - triglycerides; ASAT - aspartate aminotransferase; ALAT - alanine aminotransferase; SBP - systolic blood pressure;

DBP - diastolic blood pressure; Lys - lysine; Arg - arginine; ADMA - asymmetric dimethylarginine; * significant difference between groups.

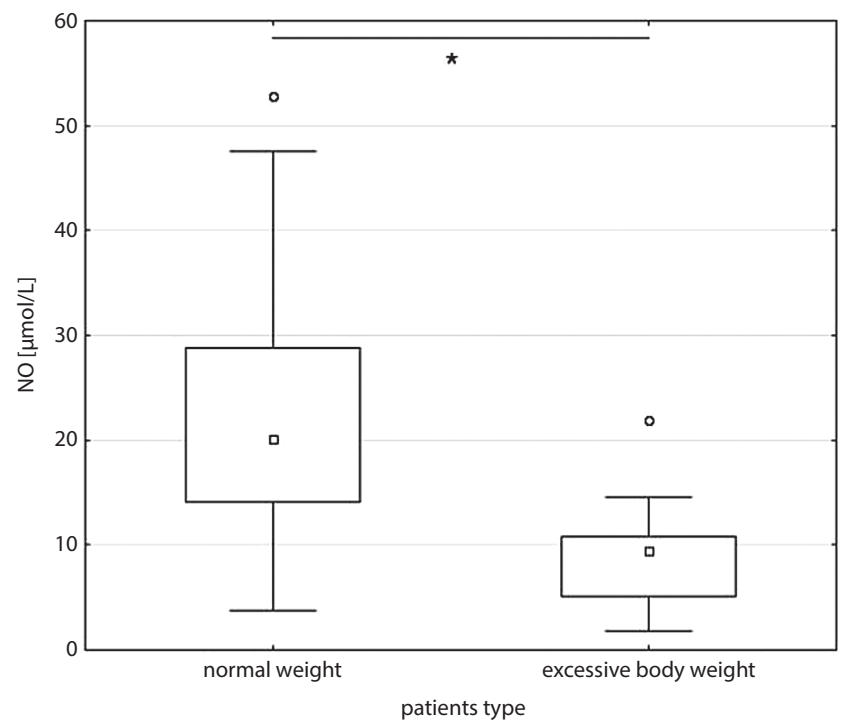

Fig. 1. Box and whiskers plot of serum nitric oxide (NO) levels in normal weight and excessive body weight (EBW) children. The boxes extend from the $25^{\text {th }}$ percentile to the $75^{\text {th }}$ percentile

$\square$ - median, $\mathbf{O}$ - outliners, ${ }^{*} \mathrm{p}<0.05$.

elevations in the levels of ALAT, creatinine, CPR, and lysine (Lys) were also shown. The lipid status of EBW children revealed an insignificant trend to increase in total 


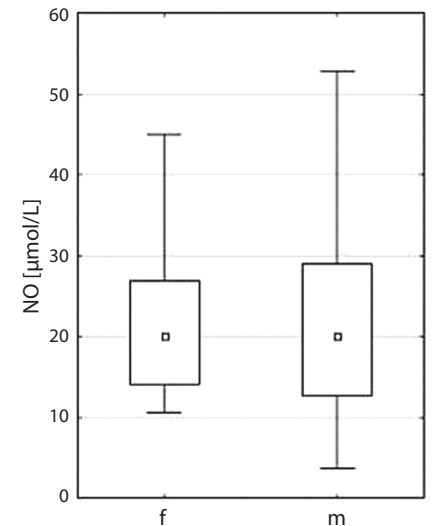

(a)

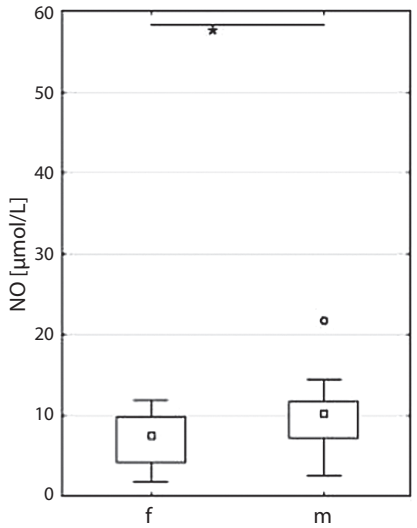

(b)
Fig. 2. Box and whiskers plot of serum nitric oxide (NO) levels in normal weight (A) and excessive body weight (EBW) (B) children divided by gender (males $-m$, and females $-\mathrm{f}$ ). The boxes extend from the $25^{\text {th }}$ percentile to the $75^{\text {th }}$ percentile

$\square$ - median, $\mathbf{0}$ - outliners, ${ }^{*} p<0.05$.

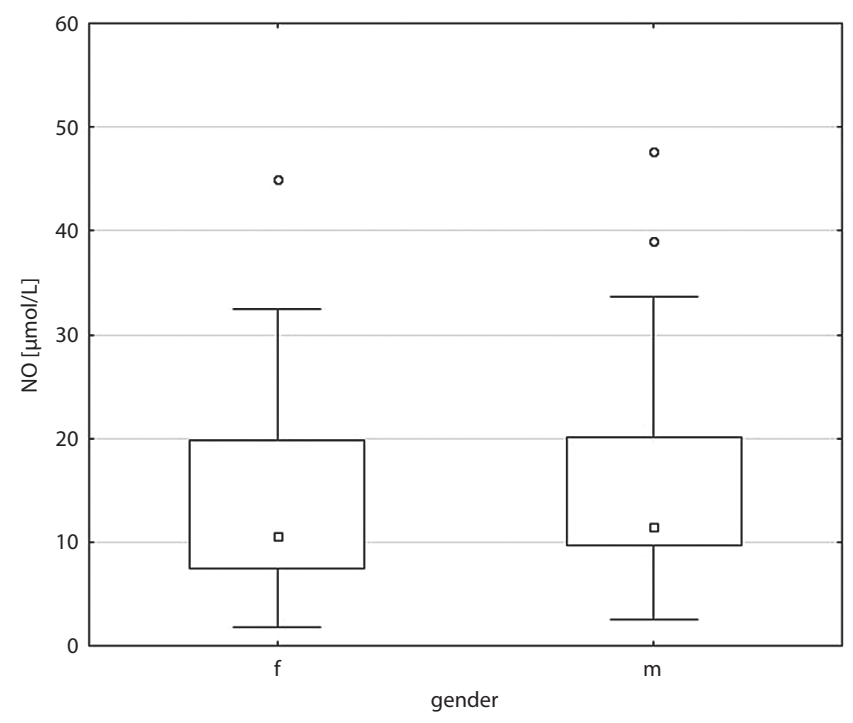

Fig. 3. Box and whiskers plot of serum NO levels in total population of the study divided by gender (males $-m$, and females $-\mathrm{f}$ ). The boxes extend from the $25^{\text {th }}$ percentile to the $75^{\text {th }}$ percentile

$\square$ - median, $\mathbf{0}$ - outliners, ${ }^{*}-p<0.05$.

cholesterol and TG. Moreover, no differences in the levels of glucose and insulin, HOMA index, ASAT, ornithine, Arg/ADMA ratio and total amino acids were observed between 2 analyzed groups.

The mean NO level in EBW group was equal to $8.7 \pm 3.1$ $\mu \mathrm{mol} / \mathrm{L}$, whereas in normal weight group the NO level was $22.2 \pm 11.5 \mu \mathrm{mol} / \mathrm{L}$. The observed difference was statistically significant (Fig. 1).

It was also investigated whether gender is associated with NO levels. The EBW male subgroup was characterized by higher level of NO than EBW female subgroup $(9.9 \pm 4.2$ and $7.2 \pm 3.0$, respectively) (Fig. $2 B)$. The observed difference was statistically significant. However, there was no significant difference in NO levels between normal weight male and female subgroups (Fig. 2A). Moreover,

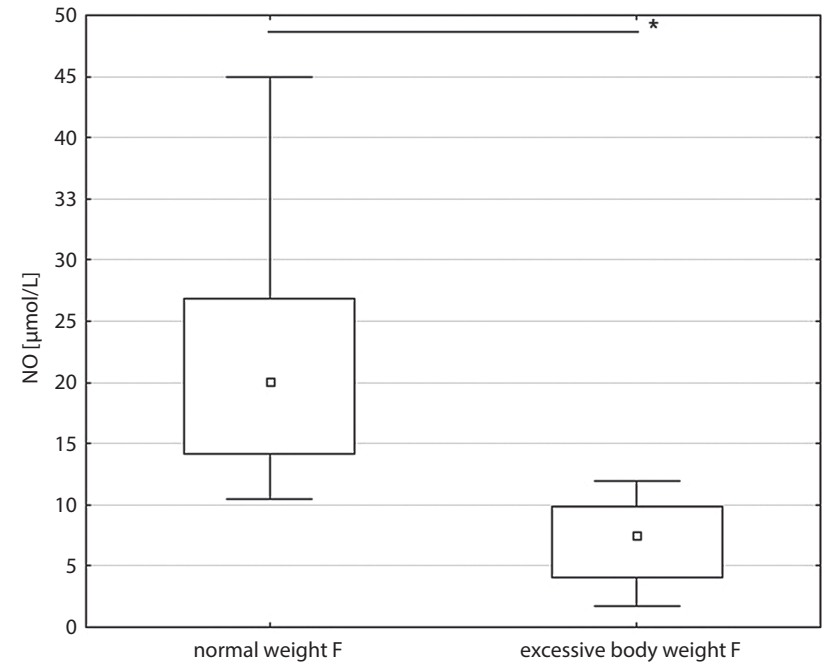

(a)

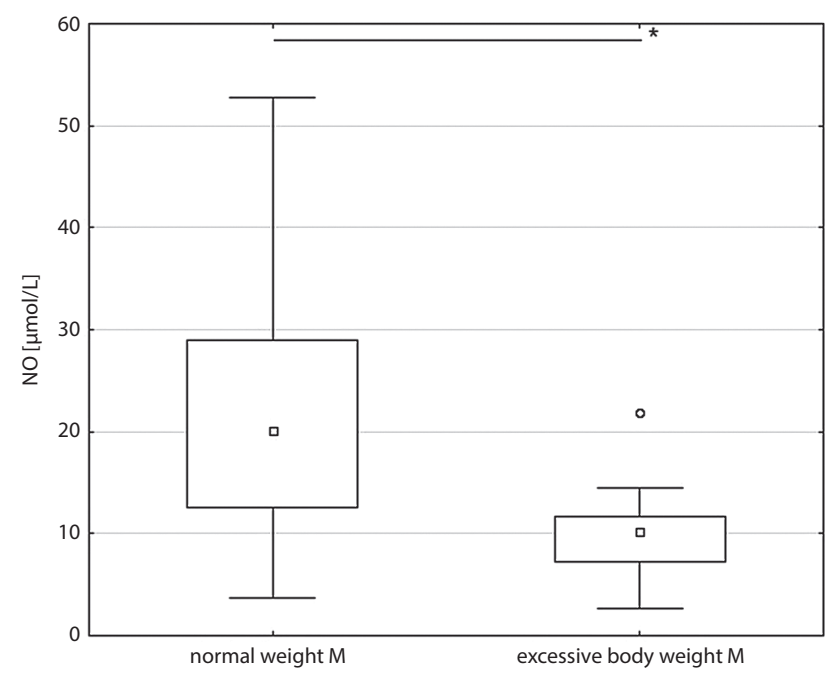

(b)

Fig. 4. Box and whiskers plot of serum nitric oxide (NO) levels in females (A) and males (B) subgroup divided by weight category (excessive body weight (EBW), normal weight)

there was no significant difference in NO levels between genders in the total population included in the study (all 80 patients) (Fig. 3). Subsequently, NO levels were analyzed with gender as a main grouping factor (Fig. 4). The normal weight female subgroup was characterized by a higher level of NO than EBW female subgroup (22.4 \pm 13.2 and $9.8 \pm 4.2$, respectively). The observed difference was statistically significant. Similar statistically significant difference was observed between normal weight male subgroup and EBW male subgroup (22.0 \pm 9.1 and 7.2 \pm 3.0 , respectively).

Levels of NO in serum among age subgroups were also investigated. There were no significant differences in NO level among age subcategories in both groups, as well as in the total population of the study (Fig. 5).

The Arg (a precursor of NO) and other amino acids levels in EBW and normal weight group were also measured. The Arg level in serum was significantly higher 


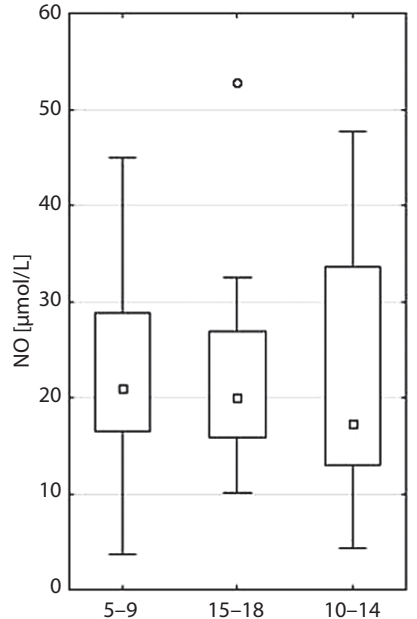

(a)

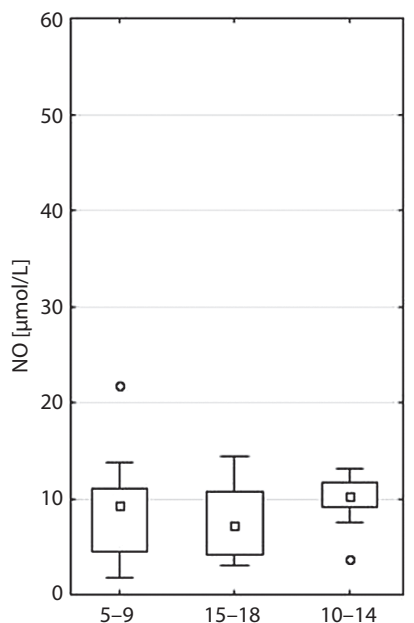

(b)
Fig. 5. Box and whiskers plot of serum nitric oxide (NO) levels in normal weight (a) and excessive body weight (EBW) (b) children divided by age (5-9, 10-14 and 15-18). The boxes extend from the $25^{\text {th }}$ percentile to the $75^{\text {th }}$ percentile

$\square$ - median, $\mathbf{O}$ - outliners.

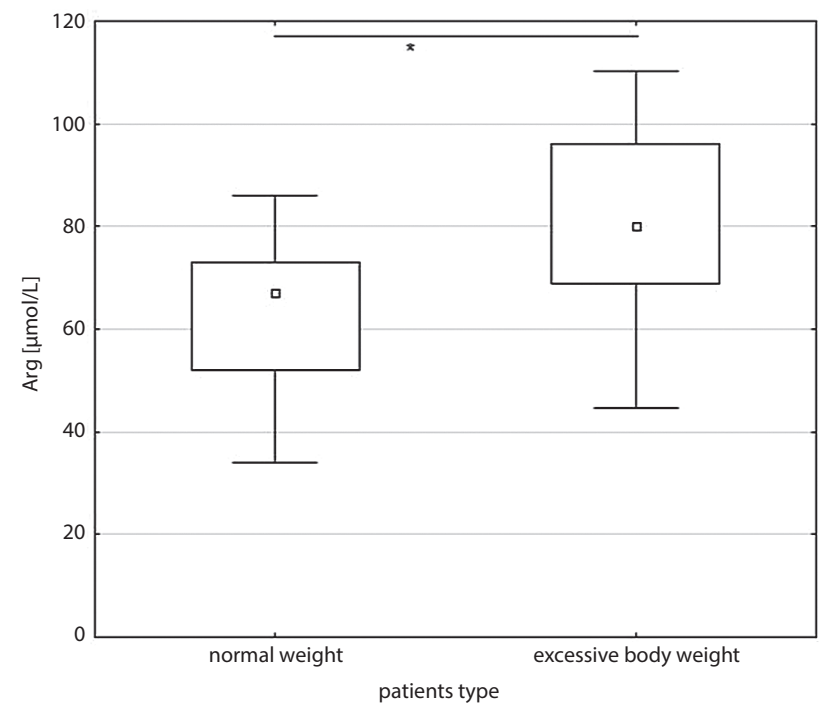

Fig. 6. Box and whiskers plot of serum arginine (Arg) levels in normal weight and excessive body weight (EBW) children. The boxes extend from the $25^{\text {th }}$ percentile to the $75^{\text {th }}$ percentile

$\boldsymbol{\square}$ - median, $\mathbf{O}$ - outliners, ${ }^{*} \mathrm{p}<0.05$.

in EBW group that in normal weight group $(82.4 \pm 17.9$ and $62.8 \pm 14.8$, respectively) (Fig. 6). Moreover, levels of aspartic acid, glutamine, alanine, valine, tyrosine, Lys, and leucine were significantly higher in EBW children than in normal weight group (data not shown).

We also measured the serum level of ADMA - a competitive inhibitor of NOS. We found significantly higher levels of ADMA in the EBW group than in controls (Fig. 7). However, the Arg/ADMA ratio did not differ between groups (Table 1).

Correlations between NO level or Arg and other biochemical characteristics in the total population of the

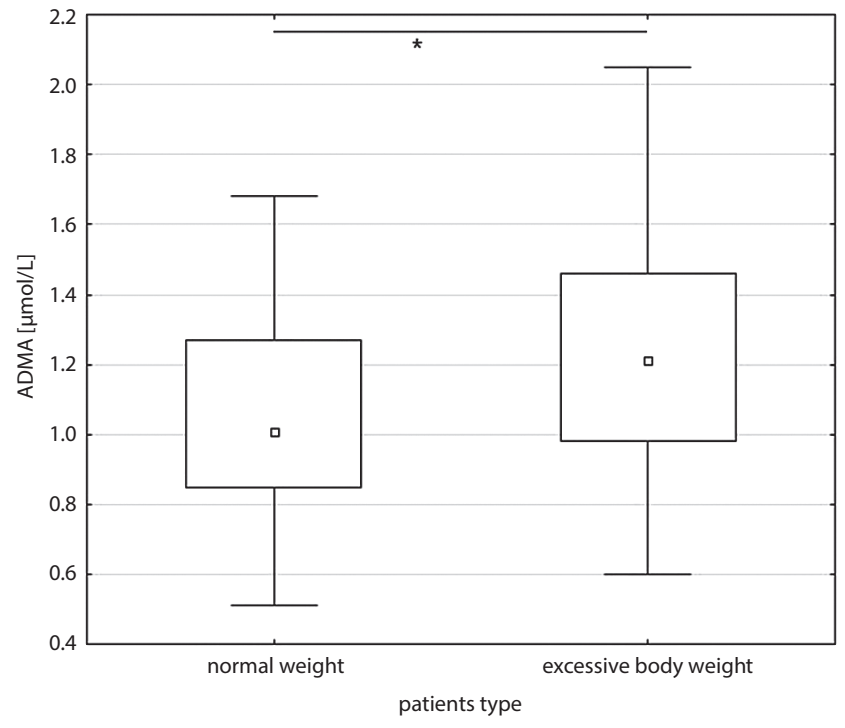

Fig. 7. Box and whiskers plot of serum asymmetric dimethylarginine (ADMA) levels in normal weight and excessive body weight (EBW) children. The boxes extend from the $25^{\text {th }}$ percentile to the $75^{\text {th }}$ percentile $\square$ - median, $\mathbf{0}$ - outliners, ${ }^{*} \mathrm{p}<0.05$.

Table 2. Pearson's analysis of correlation between nitric oxide (NO) or arginine (Arg) and selected parameters in studied subjects

\begin{tabular}{|l|c|c|}
\multicolumn{1}{|c|}{ Characteristic } & NO $[\mu \mathrm{mol} / \mathrm{L}]$ & Arg $[\mu \mathrm{mol} / \mathrm{L}]$ \\
\hline BMI $\left[\mathrm{kg} / \mathrm{m}^{2}\right]$ & $-0.501^{*}$ & $0.441^{*}$ \\
\hline Centile BMI & $-0.319^{*}$ & $0.393^{*}$ \\
\hline Weight $[\mathrm{kg}]$ & $-0.263^{*}$ & $0.298^{*}$ \\
\hline CRP $[\mathrm{mg} / \mathrm{L}]$ & $-0.312^{*}$ & $0.339^{*}$ \\
\hline Glucose $[\mathrm{mg} / \mathrm{dL}]$ & -0.134 & 0.230 \\
\hline Insulin $[\mu \mathrm{lU} / \mathrm{mL}]$ & -0.068 & 0.202 \\
\hline HOMA index & -0.072 & 0.188 \\
\hline Cholesterol $[\mathrm{mg} / \mathrm{dL}]$ & -0.221 & -0.049 \\
\hline TG $[\mathrm{mg} / \mathrm{dL}]$ & -0.001 & 0.029 \\
\hline Creatinine $[\mathrm{mg} / \mathrm{dL}]$ & -0.059 & $0.268^{*}$ \\
\hline ASAT $[\mathrm{U} / \mathrm{L}]$ & 0.032 & -0.151 \\
\hline ALAT $[\mathrm{U} / \mathrm{L}]$ & $-0.264^{*}$ & 0.144 \\
\hline SBP $[\mathrm{mm} \mathrm{Hg}]$ & $-0.343^{*}$ & $0.439^{*}$ \\
\hline DBP $[\mathrm{mm} \mathrm{Hg}]$ & -0.193 & $0.457^{*}$ \\
\hline Lys $[\mu \mathrm{mol} / \mathrm{L}]$ & -0.197 & $0.631^{*}$ \\
\hline ADMA $[\mu \mathrm{mol} / \mathrm{L}]$ & $-0.269^{*}$ & 0.100 \\
\hline NO $[\mu \mathrm{mol} / \mathrm{L}]$ & - & $-0.434^{*}$ \\
\hline B & & \\
\hline
\end{tabular}

$\mathrm{BMI}$ - body mass index; CRP - C-reactive protein; HOMA - homeostasis model assessment; TG - triglycerides; ASAT - aspartate aminotransferase; ALAT - alanine aminotransferase; SBP - systolic blood pressure; DBP - diastolic blood pressure; Lys - lysine, Arg - arginine; ADMA - asymmetric dimethylarginine; ${ }^{*}$ statistically significant correlation $(p<0.05)$.

study were tested (Table 2). The NO level was significantly and negatively correlated with BMI, CRP and SBP. The same biochemical characteristics were positively correlated with Arg level. Furthermore, the significant negative correlation was found between NO level and ADMA as well as Arg. 


\section{Discussion}

In this study, serum NO level was assessed in normal weight and EBW children. The main findings are as follows: 1. compared with normal weight children, the EBW children had significantly lower serum NO concentration; 2. in EBW children, females had slightly lower serum NO level than males; 3. serum Arg and ADMA levels were higher in EBW group. A significantly lower serum level of NO in EBW children found in our study is in line with studies which suggest a correlation between decreased bioavailability of NO and obesity, both in children and adults. ${ }^{12,18}$ However, in some publications, no changes or increase the bioavailability of NO in obese children were reported. ${ }^{11,19,20}$ According to Codoner-Franch et al., differences in NO level were caused by dissimilarities in subjects among studies, mainly regarding age. ${ }^{11}$ However, we examined children in the age comparable with the subjects studied by Codoner-Franch et al. and we obtained different results. In addition, the subjects included in our study were younger than children studied by Gruber et al., but in both studies, higher levels of NO were observed in normal weight children. ${ }^{12}$ Furthermore, we observed no differences between NO levels among age subgroups in our study (no differences within normal weight group, EBW group and total population). In our opinion, these discrepancies may be derived from analyzing obesity on different levels of progression (based on characteristics like BMI, TG, total cholesterol, high-density lipoprotein (HDL) cholesterol, low-density lipoprotein (LDL) cholesterol, and CRP). Changes in serum NO level can be a result of complex interactions between factors that regulate NOS activity, NOS mRNA stability and NO degradation. ${ }^{7}$ All those factors could differ throughout the development of obesity. It is conceivable that in the initial state of obesity there is a decline of NO level, and, after that, NO level could increase in severe obesity. In obesity increased oxidative stress is observed. This systemic stress can increase along with fat accumulation. ${ }^{21}$ Reactive oxygen species (ROS) can diminish NO bioactivity. For instance, ROS can decline the effect of NO by inactivating it directly. It has been proven that superoxide reacts with NO, and peroxynitrite is produced. This reaction both reduces the level of NO and produces more damaging ROS. Moreover, ROS can also disturb NO actions by direct competition (oxidation of the sites of protein which NO reacts with) or allosteric modulation (influence on $\mathrm{NO}$ binding sites). ${ }^{8}$ The decrease in the NO concentration beneath critical value would facilitate the activation of the compensatory mechanisms and increase NO level. Enhanced NO production may occur through induction of iNOS expression. First of all, it has been shown that NO inhibits the transcription of the gene-encoding iNOS in several cell types, which is why a decrease in NO concentration removes the inhibitory effect. $^{22-24}$ Secondly, obesity is considered an inflammatory condition and overproduction of $\mathrm{NO}$ is a consequence of inflammatory condition, since iNOS requires INF- $\gamma$, IL-1 $\beta$ and TNF- $\alpha$ for induction. ${ }^{7,25,26}$

In the current study, a significant difference was found in NO concentration between genders in EBW group. In female EBW subgroup, NO level was lower than in the male EBW subgroup. However, EBW girls were slightly older compared to EBW boys ( $12.9 \pm 3.0$ vs $10.7 \pm 3.5)$. What is surprising, despite the same age difference in the normal weight group, no differences in NO level between genders were observed in this group. There were also no differences in $\mathrm{NO}$ level among age subgroups in the general population of the study. Other authors also reported a lack of such difference between NO level and gender in the general population of their studies. ${ }^{11,20}$ It has been proven that obesity may perturb pubertal development by advancing puberty in girls and delaying puberty in boys. ${ }^{27}$ Therefore, it is reasonable to assume that puberty is somehow involved in the regulation of NO level. Since in the estimated group, the girls were slightly older than boys, puberty among girls may be more advanced and this may result in some genderrelated differences between both groups, including higher NO level in male EBW group than in female EBW group (Fig. 2B).

In our study, the serum level of Arg was significantly higher in the EBW group than in children with normal weight. This observation is in line with findings of other authors (e.g., Gruber et al.). ${ }^{12}$ Therefore, it seems that the lower level of NO cannot be explained by the lack of substrate. Moreover, we have found a negative correlation between NO level and Arg concentration in serum. This relationship between Arg (substrate) and NO (product) may be explained by the phenomenon described in the literature as "arginine paradox". ${ }^{28}$ Plasma concentration of Arg is a result of protein catabolism and synthesis from other amino acids. The majority of synthesized Arg is derived from citrulline (by argininosuccinate synthase and argininosuccinate lyase). However, it seems that an extracellular/exogenous Arg concentration (Arg transported into cells) is the major determinant of NO production. ${ }^{29-31}$ Furthermore, it has been proven that the transport of extracellular Arg by the cationic amino acid transporter I (CAT-1) can be suppressed by L-lysine. ${ }^{32}$ In our EBW group, the concentration of serum Lys was increased in comparison with normal weight children. This fact may also explain why higher concentration of serum Arg does not translate directly into higher NO production; however, only weak, nonsignificant negative correlation between serum NO and Lys was found in our subjects. Children with EBW had slightly, but significantly increased serum levels of natural NOS inhibitor - ADMA. Moreover, we found a significant inverse correlation between serum ADMA concentration and NO levels. Thus, ADMA may at least partially contribute to decreased NO levels in children with EBW. Also, other authors found a correlation between obesity and increased ADMA. ${ }^{33}$ Moreover, they found that ADMA may be implicated in the increase of blood 
pressure. It should be noted that our EBW children had also increased both ADMA and SBP. Another factor that contributes to increased $\mathrm{NO}$ synthesis is serum adiponectin concentration. ${ }^{13,34}$ Since decreased serum adiponectin level in children obesity is well-documented, it could be another reason for decreased serum NO levels in EBW children. ${ }^{35}$ The nutritional differences may also influence the serum levels of $\mathrm{NO}$ and Arg in different individuals. Unfortunately, the subjects from the control group did not fill a nutritional questionnaire, so we were unable to verify this, and this is a limitation of the study. However, all participants of the study were recruited from the same population (residents of Gdańsk and its surroundings), so we suppose that diets in both groups were generally similar. Our findings may also be limited by a relatively small number of subjects enrolled in the present study.

We found significantly increased SBP and DBP in EBW children, and a statistically significant correlation between NO level and SBP. A similar observation was made by Codoner-Franch et al., and Ghasemi and Zahediasl. ${ }^{11,19}$ This may suggest that obesity-related $\mathrm{NO}$ reduction is involved in the development of hypertension in children and may contribute to CVD development in later age. Because of the complex nature of the interactions between serum NO level and obesity, at this point, $\mathrm{NO}$ concentration has no prognostic implications as an individual marker. Further studies on the molecular mechanism of changes in serum NO level during development of obesity may increase the clinical value of this marker. However, monitoring of serum NO level in EBW and obese children together with well established CVD biomarkers (e.g., lipid profile, inflammation, arterial structural vulnerability) may be beneficial in risk assessment process. ${ }^{36}$

\section{Conclusions}

In conclusion, we showed that EBW in children is associated with decreased serum level of NO. The decreased level of NO in this group is not a result of deficient accessibility of serum Arg, but may be associated with increased serum concentration of ADMA. Our results suggest that decreased level of NO could be involved in the development of cardiovascular disorders among children with EBW. Future studies should apply analyses in a larger group of patients to evaluate the generality of the obtained results.

\section{References}

1. Toda N, Okamura T. Obesity impairs vasodilation and blood flow increase mediated by endothelial nitric oxide: An overview. J Clin Pharmacol. 2013;53(12):1228-1239.

2. Must A, Strauss RS. Risk and consequences of childhood and adolescent obesity. Int J Obes Relat Metab Disord. 1999;23:2-11.

3. Reilly JJ, Methven E, McDowell ZC, et al. Health consequences of obesity. Arch Dis Child. 2003;88(9):748-752.
4. World Health Organization. Obesity: Preventing and managing the global epidemic. WHO Technical Report Series. 2000;894:16-60.

5. European Environment and Health Information System. Prevalence of excess body weight and obesity in children and adolescents. Fact Sheet. 2007;2.3:1-4. http://www.euro.who.int/_data/assets/pdf_ file/0005/96980/2.3.-Prevalence-of-overweight-and-obesity-EDITED_layouted_V3.pdf. Accessed December 15, 2016.

6. Lundberg JO, Weitzberg E, Gladwin MT. The nitrate-nitrite-nitric oxide pathway in physiology and therapeutics. Nat Rev Drug Discov. 2008;7(2):156-167.

7. Kleinert $H$, Pautz A, Linker K, Schwarz PM. Regulation of the expression of inducible nitric oxide synthase. Eur JPharmacol. 2004;500(1-3): 255-266.

8. Elahi MM, Naseem KM, Matata BM. Nitric oxide in blood: The nitrosative-oxidative disequilibrium hypothesis on the pathogenesis of cardiovascular disease. FEBS J. 2007;274(4):906-923.

9. Konukoglu D, Uzun H, Firtina S, Arica PC, Kocael A, Taskin M. Plasma adhesion and inflammation markers: Asymmetrical dimethylL-arginine and secretory phospholipase A2 concentrations before and after laparoscopic gastric banding in morbidly obese patients. Obes Surg. 2007;17(5):672-678.

10. Pacher $P$, Beckman JS, Liaudet A. Nitric oxide and peroxynitrite in health and disease. Physiol Rev. 2007;87(1):315-424.

11. Codoner-Franch $P$, Tavárez-Alonso $S$, Murria-Estal R, Megías-Vericat J, Tortajada-Girbés M, Alonso-Iglesias E. Nitric oxide production is increased in severely obese children and related to markers of oxidative stress and inflammation. Atherosclerosis. 2011;215(2):475-480.

12. Gruber HJ, Mayer C, Fauler G, Granditis N, Wilders-Truschnig M. Obesity reduces the bioavailability of nitric oxide in juveniles. Int J Obes (Lond). 2008;32(5):826-831.

13. Belo VA, Souza-Costa DC, Lacchini R, et al. Adiponectin associates positively with nitrite levels in children and adolescents. Int J Obes Relat Metab Disord. 2013;37:740-743.

14. Cole TJ, Bellizzi MC, Flegal KM, Dietz WH. Establishing a standard definition for child overweight and obesity worldwide: International survey. BMJ. 2000;320(7244):240-1246.

15. Granger DL, Taintor RR, Boockvar KS, Hibbs JB. Measurement of nitrate and nitrite in biological samples using nitrate reductase and Griess reaction. Methods Enzymol. 1996;268:142-151.

16. Adrych K, Smoczyński M, Stojek M, et al. Decreased serum essential and aromatic amino acids in patients with chronic pancreatitis. World J Gastroenterol. 2010;16(35):4422-4427.

17. Levy JC, Matthews DR, Hermans MP. Current homeostasis model assessment (HOMA) evaluation uses the computer program. Diabetes Care. 1998;21(12):2119-2192.

18. Maniscalco M, de Laurentiis G, Zedda A, et al. Exhaled nitric oxide in severe obesity: Effect of weight loss. Respir Physiol Neurobiol. 2007; 156(3):370-373.

19. Ghasemi A, Zahediasl S. Nitric oxide and clustering of metabolic syndrome components in pediatric. Eur J Epidemiol. 2010;25(1):45-53.

20. Hrabák A, Derzbach L, Csuka I, Bajor T, Körner A. Role of nitric oxide (NO) metabolism and inflammatory mediators in childhood obesity. Inflamm Res. 2011;60(11):1061-1070.

21. Furukawa S, Fujita T, Shimabukuro M, et al. Increased oxidative stress in obesity and its impact on metabolic syndrome. J Clin Invest. 2004; 114(12):1752-1761.

22. Colasanti M, Persichini T, Menegazzi M, et al. Induction of nitric oxide synthase mRNA expression: Suppression by exogenous nitric oxide. J Biol Chem. 1995;270(45):26731-26733.

23. Park SK, Lin HL, Murphy S. Nitric oxide regulates nitric oxide synthase-2 gene expression by inhibiting NF-KB binding to DNA. Biochem J. 1997:322(Pt 2):609-613.

24. Colasanti M, Suzuki H. The dual personality of NO. Trends Pharmacol Sci. 2000;21(7):249-252.

25. Cancello R, Clément K. Is obesity an inflammatory illness? Role of lowgrade inflammation and macrophage infiltration in human white adipose tissue. BJOG. 2006;113(10):1141-1147.

26. Dandona P, Aljada A, Bandyopadhyay A. Inflammation: The link between insulin resistance, obesity and diabetes. Trends Immunol. 2004;25(1):1-4.

27. Solorzano CM, McCartney CR. Obesity and pubertal transition in girls and boys. Reproduction. 2010;140(3):399-410. 
28. McDonald KK, Zharikov S, Block ER, Kilberg MS. A coveolar complex between the cationic amino acid transporter 1 and endothelial nitric-oxide synthase may explain the "arginine paradox". J Biol Chem. 1997;272(50):31213-31216.

29. Bode-Böger SM, Scalera F, Ignarro LJ. The L-arginine paradox: Importance of the L-arginine/asymmetrical dimethylarginine ratio. Pharmacol Ther. 2007;114(3):295-306.

30. Dioguardi FS. To give or not to give? Lessons from the arginine paradox. J Nutrigenet Nutrigenomics. 2011;4(2):90-98

31. Shin S, Mohan S, Fung HL. Intracellular L-arginine concentration does not determine NO production in endothelial cells: Implications on the "L-arginine paradox". Biochem Biophys Res Commun. 2011;414(4):660-663.
32. Zani BG, Bohlen HG. Transport of extracellular L-arginine via cationic amino acid transporter is required during in vivo endothelial nitric oxide production. Am J Physiol Heart Circ Physiol. 2005;289(4): H1381-H1390.

33. de Giorgis T, Marcovecchio ML, Giannini C, Chiavaroli V, Chiarelli F, Mohn AJ. Blood pressure from childhood to adolescence in obese youths in relation to insulin resistance and asymmetric dimethylarginine. J Endocrinol Invest. 2016;39:169-176.

34. Śledziński T, Śledziński M, Smoleński RT, Swierczyński J. Increased serum nitric oxide concentration after bariatric surgery: A potential mechanism for cardiovascular benefit. Obes Surg. 2010;20(2):204-210.

35. Sledzinska M, Liberek A, Kaminska B. Adipokines and obesity in children and adolescents [in Polish]. Med Wieku Rozwoj. 2009;13(4): 244-251.

36. Vasan RS. Biomarkers of cardiovascular disease: Molecular basis and practical considerations. Circulation. 2006;113(19):2335-2362. 